(63\% male) were included in the analysis. Patients with hypertension, diabetes and known cardiac disease were excluded. All patients underwent detailed echocardiographic examination including $\mathrm{M}$-mode, pulsed-wave Doppler imaging, pulsed-wave tissue Doppler imaging and 2D speckle tracking.

Results: Age and sex distribution were not different between groups. Some demographic and disease related characteristics were shown in the table. BASDAI, BASFI, global assessment of disease activity and ASAS-HI scores were found to be similar between $r$ - and $n r-a x S p A$ patient groups. Although ejection fraction (EF) $(p=0.112)$ and the other echocardiographic variables were similar between groups, global longitudinal strain (GLS) $(p=0.045)$ were found to be different among groups (table 1). Post-hoc analysis showed that GLS was similar between nr-axSpA and control groups however GLS was significantly low in r-axSpA patients. In univariate analysis GLS was correlated with age $(p=0.025)$, EF $(p<0.001)$, peripheral arthritis $(p=0.047)$, and smoking $(p=0.019)$. However in regression only peripheral arthritis $(p=0.032)$ and $E F(p=0.015)$ were found as the independent predictors of GLS.

Abstract AB0883 - Table 1. The demographic and disease related characteristics of study groups.

\begin{tabular}{|c|c|c|c|c|}
\hline & $\begin{array}{l}\text { Radiographic } \\
\text { axSpA patients } \\
\quad(n=64)\end{array}$ & $\begin{array}{c}\text { Non-radiographic } \\
\text { axSpA patients } \\
(\mathrm{n}=27)\end{array}$ & $\begin{array}{c}\text { Control } \\
\text { subjects } \\
(n=30)\end{array}$ & $P$ \\
\hline Age, years (mean $\pm S D$ ) & $40.9 \pm 10.2$ & $37.6 \pm 9.4$ & $42.3 \pm 4.3$ & 0.056 \\
\hline $\begin{array}{l}\text { Duration of disease, years } \\
\text { (mean } \pm S D)\end{array}$ & $14.1 \pm 7.8$ & $10.6 \pm 8.1$ & $\mathrm{~N} / \mathrm{A}$ & $\mathrm{N} / \mathrm{A}$ \\
\hline BASDAI, (mean $\pm S D)$ & $2.7 \pm 2.1$ & $3.0 \pm 1.8$ & $N / A$ & $N / A$ \\
\hline BASFI, (mean $\pm S D)$ & $2.5 \pm 2.3$ & $2.6 \pm 2.0$ & $\mathrm{~N} / \mathrm{A}$ & $N / A$ \\
\hline $\begin{array}{l}\text { Ejection fraction, (mean } \\
\pm S D \text { ) }\end{array}$ & $58.9 \pm 5.2$ & $60.1 \pm 4.7$ & $61.2 \pm 4.9$ & 0.112 \\
\hline $\begin{array}{l}\text { Global Longitudinal } \\
\text { Strain, (mean } \pm S D)\end{array}$ & $20.4 \pm 3.3$ & $21.3 \pm 3.8$ & $22.3 \pm 2.5$ & 0.045 \\
\hline
\end{tabular}

Conclusions: The results of the present study showed that left ventricular function had impaired in r-axSpA patients and speckle tracking echocardiography may be a useful tool for early demonstration of left ventricular dysfunction.

Disclosure of Interest: None declared

DOI: 10.1136/annrheumdis-2018-eular.2767

\section{AB0884 $\quad$ SERUM FIBROBLAST GROWTH FACTOR-23 LEVELS WERE HIGHER IN PATIENTS WITH AXIAL SPONDYLOARTRHRITIS AND MAY BE ASSOCIATED WITH DISEASE ACTIVITY}

O. Gercik ${ }^{1}$, E. Coban ${ }^{2}$, B. Ozbek Iptec ${ }^{3}$, G. Avcioglu ${ }^{3}$, D. Solmaz ${ }^{1}$, O. Bayindir ${ }^{1}$, G. Kabadayi ${ }^{1}$, D. Kozaci ${ }^{3}$, S. Akar ${ }^{1} .{ }^{1}$ Rheumatology; ${ }^{2}$ Internal Medicine, Izmir Katip Celebi University School of Medicine, Izmir, ${ }^{3}$ Medical Biochemistry, Ankara Yıldırım Beyazıt University School of Medicine, Ankara, Turkey

Background: Axial spondyloarthritis (axSpA) is a chronic inflammatory disease that mainly affects axial skeleton. The disease is characterised by new bone formation; it usually starts with the bony fusion of sacroiliac joints (SIJs) and also causes syndesmophyte formation in the intervertebral space, enthesophytes in the tendon and ligament insertion sites. Underlying mechanisms of new bone formation in axSpA patients is not completely understood and low levels of sclerostin may be associated with the development of syndesmophyte in patients with ankylosing spondylitis (AS). Beside sclerostin another osteocyte factor is fibroblast growth factor-23 (FGF-23) and it has been first described as a phosphaturic hormone. It was also shown that FGF-23 may inhibit osteoblast differentiation and matrix mineralization

Objectives: To evaluate serum FGF-23 and sclerostin levels in patients with axSpA and to compare them with those of healthy control subjects. We also assessed relationship between the serum FGF-23, sclerostin levels and disease related variables in particular the presence of structural changes.

Methods: In total 109 axSpA patients according to ASAS classification criteria and age- and sex-matched 57 healthy control subjects were included in the analysis. Subjects with renal failure and significant comorbid conditions and axial SpA patients who were using anti-TNF agents were excluded. Demographic and disease related characteristics were collected by using a standard questionnaire. Serum levels of FGF-23 and sclerostin were measured using commercially available enzyme-linked immunosorbent assay (ELISA) kits in accordance with the supplier's instructions.

Results: In the present study there were 55 patients with non-radiographic axSpA and 54 patients with AS. Serum levels of FGF-23 levels were significantly higher in axSpA patients than healthy subjects. Although there was a trend towards a lower sclerostin levels in axSpA patients this difference did not show statistical significance (table 1). In axSpA patients serum FGF-23 levels were found to be correlated with erythrocyte sedimentation rate (ESR) $(p=0.006$ and $r=0.265)$, C- reactive protein (CRP) $(p=0.017$ and $r=0.229)$ and patients' height $(p=0.027$ and $r=-0.221$ ). There was no relationship between FGF-23 and mSASSS score or the presence of syndesmophyte. Subgroup analysis revealed that the duration of disease $(p=0.005)$, ESR $(p=0.007)$, CRP $(p<0.001)$ and mSASSS $(p=0.008)$ scores were significantly higher in AS patients than $\mathrm{nr}-\mathrm{axSpA}$ patients. However serum sclerostin levels were significantly higher in $\mathrm{nr}$-axSpA patients $(1464.4 \pm 728.1 \mathrm{vs}$ $1150.8 \pm 754.3 \mathrm{pg} / \mathrm{mL}$ and $\mathrm{p}=0.029$ ).

Abstract AB0884 - Table 1. Demographic characteristics and serum FGF-23 and sclerostin levels in study groups

\begin{tabular}{lccc}
\hline & $\begin{array}{c}\text { Axial } \\
\text { spondyloarthritis } \\
(\mathbf{n}=\mathbf{1 0 9})\end{array}$ & $\begin{array}{c}\text { Healthy } \\
\text { controls } \\
(\mathbf{n}=57)\end{array}$ & $P$ \\
\hline Mean age (years) & $39.8 \pm 10.3$ & $37.0 \pm 8.2$ & 0.055 \\
Male (\%) & 51 & 44 & 0.513 \\
Mean fibroblast growth factor-23 (pg/ & $188.5 \pm 160.7$ & $130.8 \pm 100.3$ & 0.005 \\
$\mathrm{~mL})$ & & & \\
Mean sclerostin $(\mathrm{pg} / \mathrm{mL})$ & $1309.0 \pm 754.4$ & $1365 \pm 676.7$ & 0.633 \\
\hline
\end{tabular}

Conclusions: Our results suggested that serum FGF-23 is increased in axSpA patients. And also disease activity may contribute to an up-regulation in serum FGF-23 levels.

Disclosure of Interest: None declared

DOI: 10.1136/annrheumdis-2018-eular.2828

\section{AB0885 CHARACTERISTICS OF JUVENILE ONSET HIP ARTHRITIS IN PATIENTS WITH SPONDYLOARTHRITIS}

W. Hamdi, R. Ben Saad, H. Riahi, K. Maatallah, D. Kaffel, T. Bouaziz, L. Ledab

M. Kchir institut national de Mohamed el Kassab, tunis, Tunisia

Background: Axial spondyloarthritis (AS) is a chronic inflammatory rheumatic disease that affects the axial skeleton. It typically occurs in the late teens or early twenties and rarely in childhood, defining the juvenile onset (JoAS).

The adult-onset AS (AoAS) and Juvenile-onset (JoAS) may share many common features including hip involvement. But their impact on function and quality of life may differ.

Objectives: To compare demographic, clinic and functional outcome of patients with hip involvement in JoAS, with that of patients with AoAS

Methods: Cross-sectional study including patients with AS according to the ASAS criteria of ${ }^{2009}$ with hip involvement. The juvenile onset of coxitis was defined by an onset before 16 years of age. An analysis of demographic and clinical comparisons between the two groups was performed including HLA B27 status. Mobility spine outcomes were assessed by the Bath AS Metrology Index (BASMI) and radiographic disease severity by the Bath AS Radiology Index (BASRI).

Results: There were 100 AS aged on average $36.4 \pm 12,2$ years old. ${ }^{16-69}$ The sex ratio was 4.6. The mean duration of progression of AS was $10.93 \pm 9,89$ years [0.5-24]. It was a JoAS in 15 cases. All patients had a hip involvement. The juvenile onset of hip arthritis was associated with male gender $(p=0,042)$, younger age of patient with AS at the time of recruitment $(p=0,007)$, less severe clinical spinal involvement assessed by schober index $(p=0,029)$ and more frequent and severe enthesitis assessed by MASES $(p=0,024)$. Extra-articular manifestations were significantly more frequent in patients with juvenile onset of hip arthritis $(p=0,008)$ Otherwise the comparison of the two groups showed no difference in the pres ence of uveitis $(p=0,407)$ and pulmonary involvement $(p=0,097)$. HLAB27 antigen was significantly more common in JoAS $(p=0,037)$. BASRI and BASMI as well as ESR and CRP, were comparable between the two groups $(p=0,976, p=0,626$, $\mathrm{p}=1,000$, respectively)

Conclusions: Hip involvement is common in the AS, particularly in JoAS. Our study showed that juvenile onset hip arthritis was associated with male gender less severe spine involvement, enthesitis and the presence of HLA B27. This would help physicians to identify patients at higher risk of developing hip involvement, to enable early diagnosis.

\section{REFERENCES:}

[1] Gensler LS, Ward MM, Reveille JD, Learch TJ, Weisman MH, Davis JC, $\mathrm{Jr}$. Clinical, radiographic and functional differences between juvenile-onset and adult-onset ankylosing spondylitis: results from the PSOAS cohort. Ann Rheum Dis. 2008;67(2):233-7.

[2] Stone M, Warren RW, Bruckel J, Cooper D, Cortinovis D, Inman RD. Juvenile-onset ankylosing spondylitis is associated with worse functional outcomes than adult-onset ankylosing spondylitis. Arthritis Rheum. 2005;53 (3):445-51.

Disclosure of Interest: None declared

DOI: 10.1136/annrheumdis-2018-eular.5872 